\title{
Communicating the Right Therapy for the Right Patient at the Right Time: Acute Therapy
}

\author{
Fred D. Sheftell
}

\begin{abstract}
Objective: Review of problems arising from communication difficulties in headache practice. Methods: Literature review and assessment of practice experience. Background: Advances in understanding of the pathophysiology of migraine and the availability of specific acute therapies have given migraine sufferers access to effective treatment and physicians a wide array of therapeutic alternatives. There remains uncertainty about the best drug group for any given patient and about which triptan to use when and in which formulation; about patient preference and satisfaction; about interpretations of pivotal trials and meta-analyses; and about the relevance of large group efficacy and safety data to the individual patient. The clinician may be daunted by the array of triptans with choices of dosage and multiple formulations and will likely learn how to use two or three of them at most, as in depression and hypertension. In the context of the wide array of choices and the complexities of assessing responses and patient preferences, this paper attempts to provide a framework for incorporating the evidence with clinical experience and for communicating these concepts effectively. Benefits, Harms and Costs: None. Results and Conclusion: Even when an appropriate recommendation is determined, therapy may fail unless the doctor patient relationship permits open communication, time for questions and answers and time for instruction on how to use a given medication, and its probable effects. Translating evidence into patient-friendly language is a skill as necessary as that of making the clinical decision itself. Tools are available that can support this effort and aid in creating an environment of "partnership".
\end{abstract}

RÉSUMÉ: Communiquer le bon traitement au bon patient au bon moment: le traitement de la phase aiguë. Objectif: Revoir les problèmes résultant de difficultés de communication dans la pratique auprès de patients souffrant de céphalée. Méthodes: Revue de la littérature et évaluation de l'expérience en pratique. Contexte: Les progrès dans la compréhension de la physiopathologie de la migraine et la disponibilité de traitements aigus spécifiques ont fourni aux migraineux un accès à un traitement efficace et aux médecins un vaste choix de thérapies. L'incertitude persiste quant au meilleur groupe de médicaments à prescrire pour un patient donné et quel triptan utiliser, quand et sous quelle forme; à la préférence et la satisfaction des patients; à l'interprétation d'essais cliniques clés et de méta-analyses; et à la pertinence pour un patient des données d'efficacité et de sécurité provenant de groupes importants de patients. La panoplie de triptans à multiples dosages et formulations peut rebuter le clinicien. Il apprendra probablement à se servir de deux ou trois médicaments tout au plus, comme c'est le cas dans la dépression et l'hypertension. Dans le contexte d'un vaste choix et de la complexité de l'évaluation de la réponse et des préférences du patient, cet article tente de fournir un modèle pour l'intégration des données et de l'expérience clinique, et pour la communication efficace de ces concepts. Bénéfices, risques et coûts: Aucun. Résultats et Conclusion: Même quand une recommandation appropriée est faite, le traitement peut échouer si la relation médecin-patient ne permet pas la communication ouverte et n'inclut pas un temps pour les questions et les réponses, pour enseigner la façon d'utiliser un médicament et aviser le patient des effets secondaires probables. Vulgariser l'information dans un langage accessible au patient est une habileté aussi nécessaire que celle de prendre la décision clinique ellemême. Des outils sont disponibles pour supporter cette initiative et aider à créer un environnement de partenariat.

Can. J. Neurol. Sci. 2002; 29: Suppl. 2 - S33-S39

\section{The EVIDEnCE: A brief overview}

Currently available therapies for the acute treatment of the migraine attack have shown them to be effective and welltolerated both in clinical trials $\mathrm{s}^{1,2}$ and in practice. The triptans and DHE have been assessed in terms of rapidity of headache response (from moderate or severe to mild or pain-free) and "sustained" pain-free response (from moderate to severe to painfree with no recurrence and no use of rescue medication), recurrence (pain returns to moderate or severe from mild or no pain within 24 hours), tolerability and adverse events, and consistency across multiple attacks. ${ }^{3}$ "The practice of evidence- based medicine means integrating individual clinical expertise with the best available external clinical evidence from systematic research." 4 Thus a balance must be struck to provide the most effective and sensible approach to clinical practice. Clinical decisions should be based on clinical experience (including knowledge of the individual patient and attack characteristics);

From the New England Centre for Headache, Stamford, CT06902 USA

Reprint requests to: FD Sheftell, 778 Long Ridge Road, Stamford, CT06902 USA 
critical appraisal of the evidence; and patient preferences. The recent evidence-based "US Headache Consortium Goals of Acute Migraine Treatment"5 lists as goals the rapid and consistent headache relief without recurrence; restoration of the patient's ability to function; minimised use of back-up and rescue medications; optimised self-care with reduction in the subsequent use of resources; cost-effective management and achievement of minimal adverse events.

Silberstein ${ }^{6}$ determined that quick relief, decreased pain and decreased recurrence rates were the top three patient goals, and oral ingestion the preferred formulation but, even with ideal medications, the role of the physician cannot be overestimated. Characteristics of the "ideal" physician identified by patients include humaneness, technical competence and outcome of care. ${ }^{7}$ Since outcome depends on adherence to prescribed regimens, proper instruction on appropriate use is vital.

\section{Pivotal Studies and Patient Preferences}

Studies of triptans have used the traditional end-point of twohour headache response and the newer end-point of sustained pain-free response. ${ }^{1,8-10}$ Tables 1 and 2 summarise these data and include therapeutic gain (TG) and 'number needed to treat' (NNT). ${ }^{11-13}$ Therapeutic gain is derived from subtracting placebo rates from active rates, NNT is the reciprocal of TG, and both have been used to compare agents in the same class in the absence of direct head-to-head trials. However, recording of the change from severe/moderate $(3 / 2)$ to mild or no head pain $(0 / 1)$ is not adequate to compare the properties of $5 \mathrm{HT}_{1 \mathrm{~B} / 1 \mathrm{D}}$ agonists because variable placebo response rates distort meta-analytic comparisons when TG and NNT are the critical variables. ${ }^{11}$ Using therapeutic gain as a basis for comparison, the minute differences in the oral triptans'two hour headache responses are unlikely to be clinically meaningful. ${ }^{13}$

Table 1: Oral Triptans - Clinical Results

\begin{tabular}{lccccc}
\hline Triptan & Dose, $\mathbf{m g}$ & 2h HA response \% & 4h HA response (\%) & 2h Pain-free (\%) & Recurrence rate (\%) \\
Sumatriptan & 50 & $52-64$ & $68-78$ & $14-30$ & $18-32$ \\
Sumatriptan & 100 & $46-69$ & $71-79$ & $14-27$ & $30-57$ \\
Zolmitriptan & 2.5 & $62-65$ & $57-75$ & $23-39$ & $15-37$ \\
Zolmitriptan & 5 & $62-67$ & $73-77$ & $12-18$ & $27-32$ \\
Naratriptan & 2.5 & 48 & $58-64$ & $16-24$ & $19-28$ \\
Rizatriptan & 5 & $60-67$ & $73-79$ & $24-44$ & $33-47$ \\
Rizatriptan & 10 & $67-77$ & $81-85$ & $28-32$ & $28-47$ \\
Eletriptan & 40 & $54-65$ & Not available & $34-48$ & $19-34$ \\
Eletriptan & 80 & $59-77$ & Not available & $28-39$ & $16-32$ \\
Almotriptan & 12.5 & $57-65$ & Not available & Not available & $18-30$ \\
Frovatriptan & 2.5 & $36-48$ & $55-66$ & & $9-14$ \\
\hline
\end{tabular}

From Tepper SJ, Rapoport AM. The triptans: a summary. CNS Drugs. 1999;12(5):403-417 with permission.

$\mathrm{HA}=$ headache

Table 2: Summary: 2 Hour Efficacy, Placebo, TG, NNT Range

\begin{tabular}{|c|c|c|c|c|c|c|}
\hline Drug & Delivery & Dose & Active & Placebo & Therapeutic Gain & NNT \\
\hline Sumatriptan & $\mathrm{SC}$ & $6 \mathrm{mg}$ & $81-82 \%$ & $31-39 \%$ & $43-50 \%$ & $2-2.3$ \\
\hline \multirow[t]{2}{*}{ Sumatriptan } & TABLET & $25 \mathrm{mg}$ & 52 & $17-27$ & $25-35$ & $2.9-4$ \\
\hline & & $100 \mathrm{mg}$ & $56-62$ & $17-26$ & $30-40$ & $2.5-3.3$ \\
\hline \multirow[t]{2}{*}{ Sumatriptan } & IN & $20 \mathrm{mg}$ & $55-64$ & $25-36$ & $24-39$ & $2.6-4.2$ \\
\hline & PR & $25 \mathrm{mg}$ & 70 & 39 & 41 & 2.4 \\
\hline Zolmitriptan & TABLET & $2.5 \mathrm{mg}$ & $62-65$ & $34-36$ & $26-31$ & $3.2-3.8$ \\
\hline Naratriptan 2 hrs & TABLET & $2.5 \mathrm{mg}$ & $43-50$ & $18-27$ & $16-28$ & $3.6-6.3$ \\
\hline \multirow[t]{4}{*}{ Rizatriptan } & TABLET & $5 \mathrm{mg}$ & $60-63$ & $23-40$ & $20-40$ & $2.5-5$ \\
\hline & & $10 \mathrm{mg}$ & $67-77$ & $35-40$ & $27-40$ & $2.5-3.7$ \\
\hline & MLT & $5 / 10 \mathrm{mg}$ & 66 & 47 & 19 & 5.3 \\
\hline & & & 74 & 28 & 46 & 2.2 \\
\hline
\end{tabular}

Sheftell FD. USPI, European and Canadian Data

$\mathrm{TG}=$ therapeutic gain;NNT $=$ number needed to treat; $\mathrm{SC}=$ subcutaneous; $\mathrm{IN}=$ intranasal; $\mathrm{PR}=$ per rectum; MLT = melt 


\section{Examples of Strategies}

\section{STEP-CARE}

Attack 1: ASA, APAP, Non-Rx NSAID

Attack 2: Combined OTC analgesics

Attack 3: Rx NSAIDs

Attack 4: Mixed butalbital, isometheptene, etc

Attack 5: Opiates/Opioids

Attack 6: Ergotamine tartrate

Attack 7: DHE-45

Attack 8: Triptans

\section{STAGED-CARE}

\section{ATTACK}

Stage 1: Combined OTC analgesics

Stage 2: NSAID

Stage 3: Ergot, DHE or Triptan

Stage 4: Rescue Therapy Opiate/Opioid, Steroid

\section{STRATIFIED CARE}

\section{ATTACK}

First-line Therapy:

Start with therapy suited for attack profile, associated symptoms, and level of disability

Move to Staged-Care for Rescue Therapy

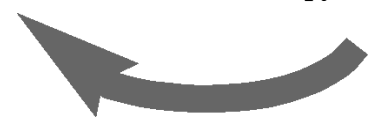

Figure 1: Examples of Strategies

Strategies have been traditionally divided into step-care starting with nonspecific, inexpensive agents and moving up with each failure to other agents and lastly specific agents; staged-care (or stepped within attacks) starting with nonspecific agents and moving to more specific agents for the same attack; and stratified care, basing acute therapy on attack characteristics, associated symptoms, and disability. The latter is preferred by most experts. (Modified from Sheftell FD, Fox AW. Acute Migraine Treatment: A Clinician'sView. Cephalalgia 2000;20(Suppl 2):14-24 and reprinted with permission from Cephalalgia).

Statistical significance may not equate with clinical significance. For example a p value of .00001 would have no clinical significance in a hypothetical study of two antihypertensives, where blood pressures achieved were 115/75 and $120 / 80$ in the two groups. Patient satisfaction and preference are likely based on multiple factors, not just the two hour headache response or even 'sustained pain-free' figures. While currently available agents decrease migraine-related disability and improve quality of life, patient responses are highly individual and do not always correlate with group data nor with metaanalytic comparisons.

In the pivotal trials, patients were instructed to wait until the headache was moderate or severe before medicating but in clinical practice they are instructed to medicate as soon as pain occurs. Retrospective data ${ }^{14-17}$ indicate that early intervention produces higher pain-free rates, lower recurrence and fewer adverse events.

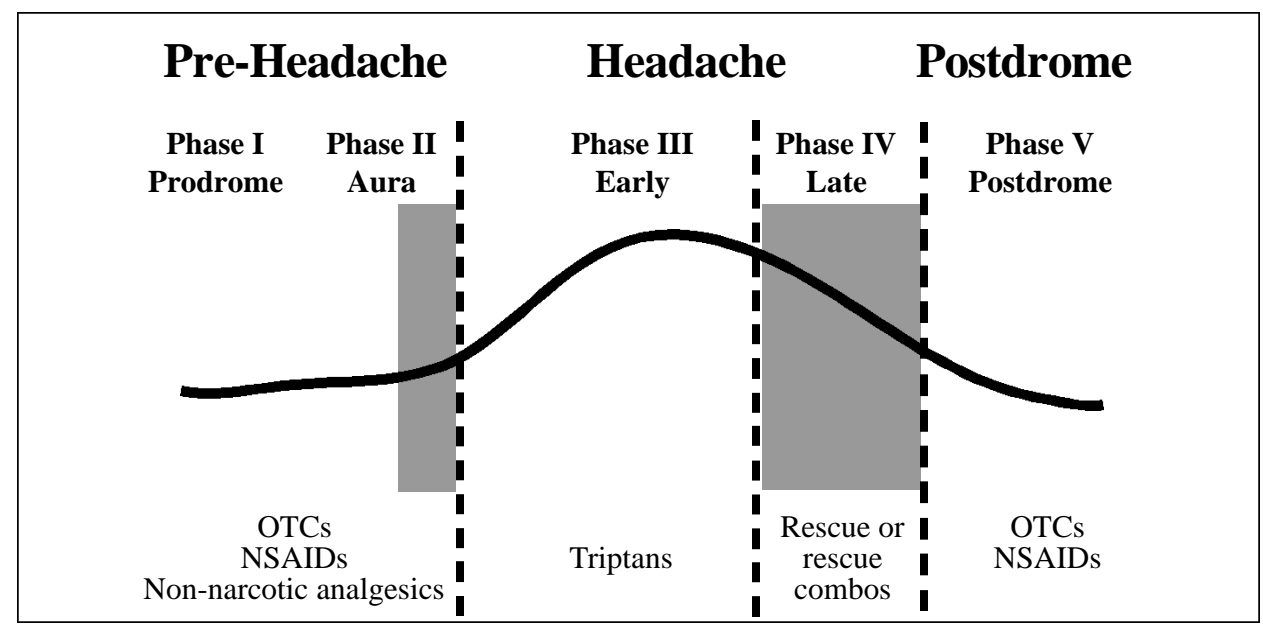

Figure 2: Therapeutic Phases of Migraine.

Using N. Blau's division of the migraine attack into several phases Cady and Farmer ${ }^{19}$ suggest a variety of therapies based on the phase of attacks. The author's clinical experience shows that "seasoned" migraine patients tend to come on this strategy by experience and know "when to use what". 


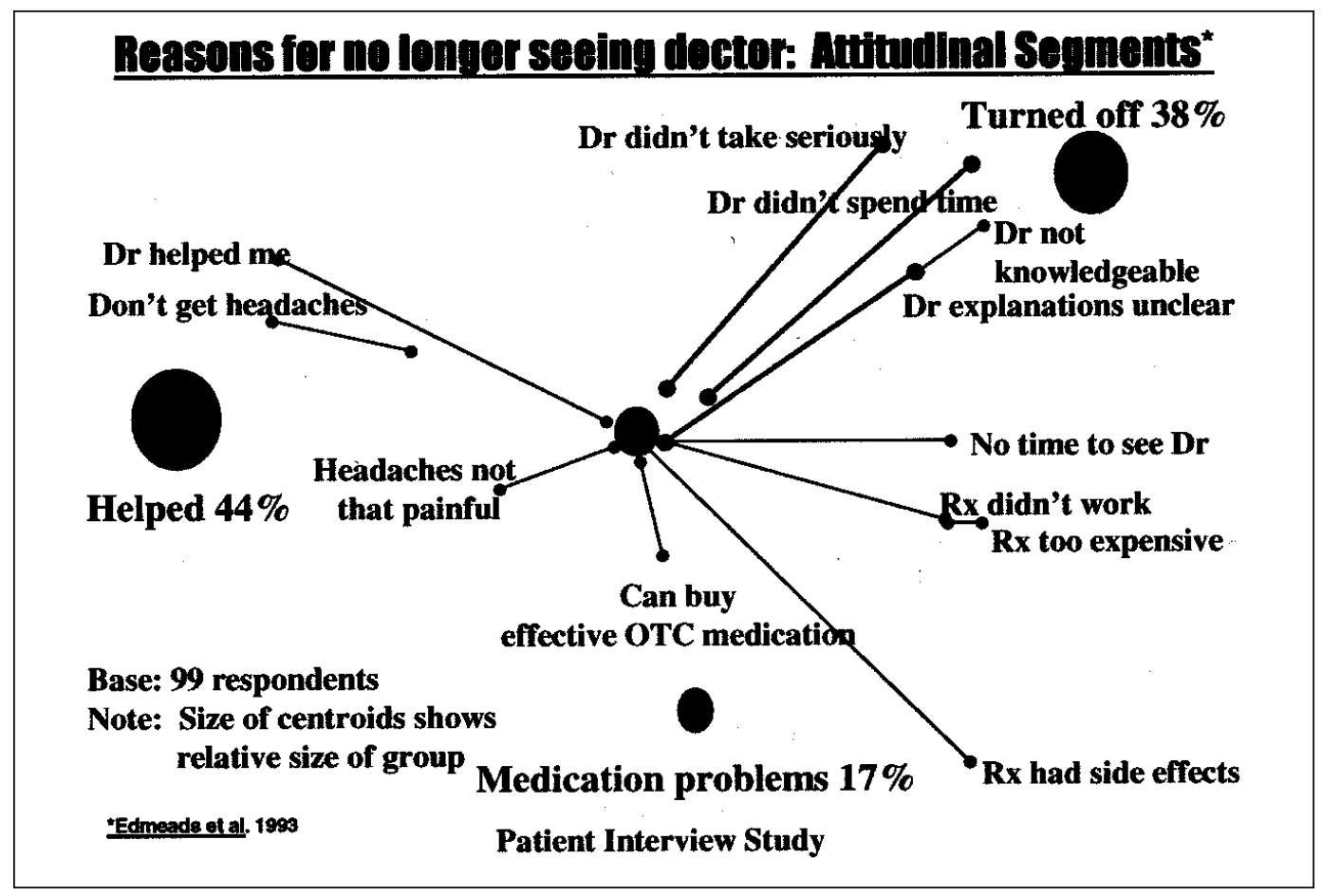

Figure 3: Reasons For No Longer Seeing The Doctor: Attitudinal Segments

From a Canadian population study asking patients with headache to identify reasons for not consulting or lapsed consulting behaviors. ${ }^{23}$ The proportions are represented by the size of the centrum.

\section{GENERALPRINCIPLES OF ACUTE CARE}

\section{Choice of strategy, formulation, and agent}

The US Consortium Guidelines ${ }^{5}$ advise physicians to pick the best agent for each individual patient, based on attack intensity, associated symptoms, associated disability and preference for formulation, to treat early for more consistent and improved efficacy and to prescribe appropriate doses. To accomplish the above, three strategies have been employed (Figure 1). ${ }^{18}$

Stepped care, which uses nonspecific, low cost therapies such as nonprescription agents, regardless of attack characteristics, associated symptoms or associated disability, moving on to more powerful agents until successful treatment has been achieved. However, this is not cost-effective, generates unnecessary disability and pain, increases patient dissatisfaction and lapsed consultation, and may lead to increased emergency room visits, as well as calls and office visits.

Staged care (stepped within attacks). Here, nonspecific agents are used first, failure being the indication to go on to specific therapy for the same headache attack. This strategy ignores data gleaned from early intervention paradigms ${ }^{13-16}$ but does allow rescue therapy.

Stratified care advocates prior careful assessment of the characteristics of acute attacks, associated symptoms and disability and prescription of more or of less specific agents as appropriate for the likely attack severity. Lipton et $\mathrm{al}^{18}$ demonstrated the superiority of this model over the other two.

A "phase specific model" based on Blau's concept of the 'phases of migraine'20 represents yet another approach. (Figure 2).

Any of the acute agents chosen needs to be given an adequate trial - in at least in two separate attacks. Both time of intervention and correct dosing are important factors influencing success rates. For example, failure to respond adequately to 50 mg sumatriptan or $2.5 \mathrm{mg}$ zolmitriptan po. may require doubling of the dose in the next attack. A 20-minute rest after medicating improves efficacy. Sometimes different formulations of the same agent may be indicated for different attacks.

\section{Patient satisfaction and preference}

Patient satisfaction and preference reflect efficacy, recurrence rates, time to recurrence, consistency of response across multiple attacks, formulation, tolerability/adverse events and achievement of restoration of full function. ${ }^{21}$ Each patient should be "debriefed" after treating a few attacks to assure that the right choices have been made. Consistent lack of efficacy may require a change in the agent, addition of an NSAID and/or pro-kinetic agent or earlier intervention. If recurrence is an issue, consider earlier intervention or an agent with a longer half-life. For adverse events, agents with better tolerability may be substituted.

\section{Communication (Translating the Evidence)}

\section{Overview}

The comment that "Any style will be effective providing it clearly demonstrates to the patient that the physician is interested 


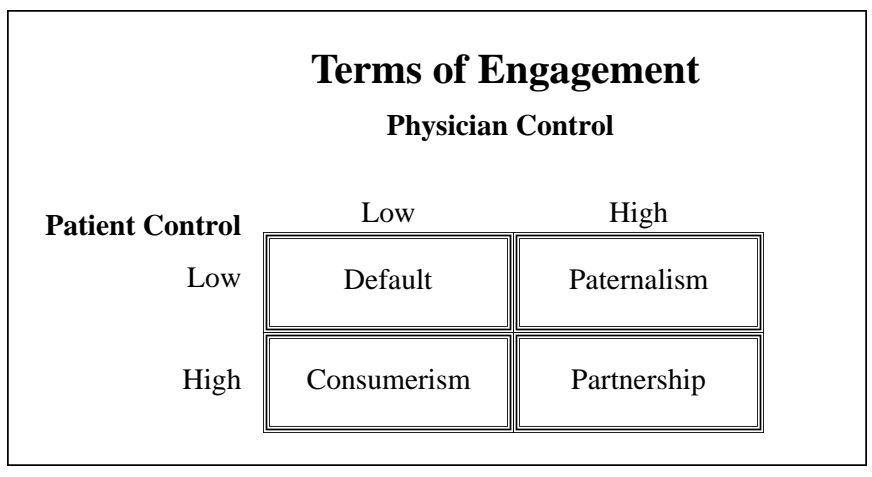

Figure 4: Terms of Engagement

A variety of descriptors for doctor/patient relationships based on control are depicted here. Default occurs when both doctor and patient take passive roles. Consumerism is where patients come in with a "shopping list" of requests which they expect the doctor to fulfill. Paternalism/maternalism implies that the doctor is clearly in charge, patients assuming a passive, compliant position. In partnership, both doctor and patient take active roles in treatment strategizing and decision making - the gold standard for improved outcomes.

From Roter and Hall

in him and his life as a person, as well as in the details of the medical complaint." ${ }^{22}$ re-affirms the claim of Hall and Domans ${ }^{7}$ that patients regard "humanity" as among the most desirable traits of the physician. This was also noted by Edmeads et $\mathrm{a}^{23}$ who showed that discontinuation of treatment was related to perceptions that the physician didn't take the complaint seriously, didn't spend time, was not knowledgeable or gave unclear explanations (Figure 3).

\section{Styles of "engagement"}

Control is one aspect of the doctor-patient relationship ${ }^{24}$ (Figure 4). When physician control is high and patient control low, the relationship may be paternalistic ("doctor knows best"); patients who want to be told what to do will be attracted to this style. With the opposite style, ("consumerism") physician control is low and patient control high, the patients specifying what management plan would be acceptable. In a default relationship, both patient and physician control are low and therapy enters a state of paralysis, but in a "partnership" style, the physician and the patient work together for improvement. The patient has a strong internal 'locus of control' and recognises that keeping calendars, tracking triggers, recording headache frequency, intensity and intake, and making life-style and dietary changes are all their responsibility. Those with external loci of control rely on the physician to make them better using some "magic bullet" but do not accept such responsibilities and will not improve until these attitudes are modified.

Patient expectations regarding headache impact, treatment effects and the physician's role need to be defined at the first appointment. Physicians should also communicate their expectations of the patient in regard to appointments, medication use and limits, refill policies, calendars etc. Both patient and physician expectations impact upon treatment outcomes; failure

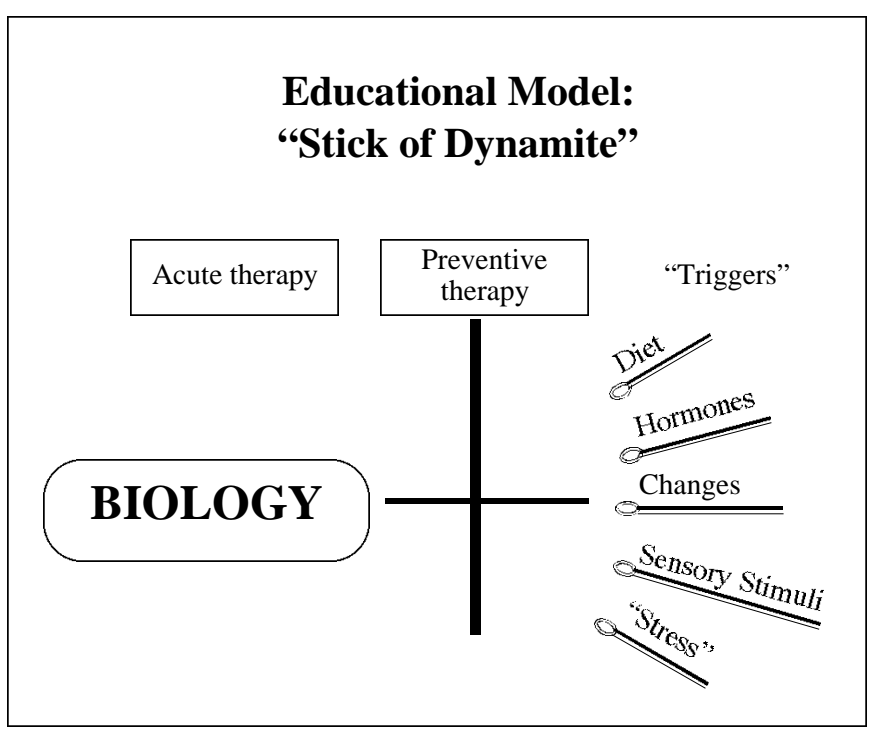

Figure 5: Educational Model: The "Stick of dynamite"

This patient education model is based on that proposed by the late Dr. John Graham. The dynamite represents biologic vulnerability, triggers are represented by matches that may light the fuse; preventive therapies as measures to prevent or reduce the number of explosions; and acute therapies to limit the extent of the explosion.

to understand patient preferences may reduce adherence but understanding patient expectations will help match treatments to needs. ${ }^{25}$ Question-asking by the patient is inversely related to the amount of information given by the physician. Better instructions are provided to consumers for the proper utilisation and maintenance of a new camera or automobile than to patients in regard to the drugs they receive. ${ }^{24} \mathrm{~A}$ medication instruction checklist describing the name, purpose and mode of use of the medication, its likely wanted and unwanted effects and other cautions etc. are of proven benefit in maximising adherence and improving treatment outcome. ${ }^{26}$ Specific written instructions have been helpful as a reminder to patients of appropriate usage.

\section{Tools}

Patient education tools are available through advocacy groups, industry, the internet and books. They include dietary regimens, calendars that record frequency, intensity, duration, trigger factors including menses and disability; medication instruction sheets, exercise regimens, and information on vitamin and nutritional supplements. Such data should be given to patients at their first visit along with direction to appropriate internet sites and patient organizations for additional information. Patients must be encouraged to take an active role in their own treatment and to manage their attacks independently wherever they occur, so that in a sense the patient is the primary caregiver in the absence of a health care provider. Plans reviewing appropriate behaviours during attacks and specifying back-up medication or rescue therapies may avoid the need for emergency room interventions.

Instruments such as the Migraine Disability Assessment Scale $\left(\right.$ MIDAS) ${ }^{27}$ and the Headache Impact Test (HIT) ${ }^{28}$ are available both on the internet and as office-based paper tools; both are excellent in assessing impact and disability. They are simple to 
use and score, help to provide a vehicle for communication, perhaps aid in diagnosis and treatment strategies and are useful in assessing patient progress over time and measuring outcomes.

A simple educational tool is depicted in Figure 5, in which migraine is conceptualised as a biological "stick of dynamite". Many factors (triggers) may ignite the fuse, "exploding" the dynamite and these must be identified and minimised. Preventive therapy is used to decrease attack frequency and intensity, and acute therapy to "contain the explosion".

\section{Case vignette}

DB is a 32-year-old married male with a history of headache since the age of eight years, that made him miss school occasionally. Escalation in frequency occurred at college. His sister has a history of similar headaches associated with her menstrual cycle and his mother had a history of disabling headache as a younger woman. DB's headaches have always been unilateral, throbbing, with severe nausea and occasional vomiting. Associated symptoms include rather severe photophobia and phonophobia. The episodes now occur almost exclusively on weekends, rarely interfering with his ability to work during the week. Though episodes are "occasional", he cannot predictably or confidently anticipate being able to "make plans" for weekends. He finds that over-the-counter agents have not helped. Clinical examination is normal. Migraine Disability Assessment Score (MIDAS) and HIT scores demonstrated that headaches were having a severe impact on his life.

\section{Discussion}

Clearly, this case of recurrent disabling headache, with no change in pattern over the years, with a negative examination, should immediately lead the clinician to suspect migraine fulfilling International Headache Society ${ }^{29}$ criteria. A positive family history is another "comfort" sign. The reasons for the diagnosis were explained thoroughly and the "dynamite" model was used to explain mechanisms and treatment rationales, including reduction of trigger factors such as diet, schedules and stress. Given the diagnosis, level of impact and lack of any contra-indications, an oral triptan was prescribed. Dosage, limits, and instructions for a minimum of two trials were discussed thoroughly and he was instructed to medicate as early as possible into the pain-phase of attacks.

On follow-up he had improved significantly. Early intervention prevented disability and resolved the attacks within two hours. The MIDAS and HIT scores showed improvement. Other than mild tingling sensations (about which he had been told) he tolerated the medication very well. He reported a remarkable improvement in quality of life and could now more confidently plan activities on weekends, much to the delight of his family.

\section{Comment}

The best practice of medicine combines knowledge of the evidence with clinical experience and expertise. Data from pivotal studies show that the current acute therapies are efficacious and well-tolerated and represent a giant step in our ability to abort the acute episode quickly and to minimise or prevent disability. However, responses to different agents are highly individual and patient preferences and satisfaction are likely based on a variety of parameters and not simply two hour headache response rates. One should be cautious in generalising group data to individual patients. Numerous tools are available to assist the physician in assessing impact and disability and to maximise adherence and efficacy related to acute therapy. The best agent is always that which works best for any given patient. The best practice of medicine occurs within a solid, open, physician/patient relationship, characterised by mutual respect and partnership.

\section{ACKNOWLedGement}

Dr F. Sheftell is serving, or has served, as an advisory board member, clinical investigator and/or speaker for GlaxoSmithKline, Merck Sharp \& Dohme, Pfizer, AstraZeneca and Pharmacia.

\section{REFERENCES}

1. Tepper SJ, Rapoport AM. The triptans: a summary. CNS Drugs 1999;12(5):403-417.

2. Physician's Desk Reference. 54th ed. Montvale (NJ): Medical Economics Company. 2000.

3. Tfelt-Hansen P, Bousser M-G, Solomon S, et al. Guidelines for controlled trials of drugs in migraine. In: International Headache Society Members Handbook. International Headache Society Committee on Clinical Trials in Migraine: Oslo, Norway: Scandanavian University Press; 1998/99: 111-120.

4. Sackett DL, Richardson WS, Rosenberg W, Haynes BR. Evidencebased Medicine. How to Practice \& Teach EBM. Edinburgh, London, New York, Philadelphia, Sydney, Toronto: Churchill Livingstone. 1999.

5. Silberstein SD, for the US Headache Consortium. Practice parameter: evidence-based guidelines for migraine headache (an evidence-based review): report of the Quality Standards Subcommittee of the American Academy of Neurology. Neurology 2000;55:754-762.

6. Silberstein SD. Migraine symptoms: results of a survey of selfreported migraineurs. Headache 1995;35:387-396.

7. Hall JA, Doman MC. Meta-analysis of satisfaction with medical care: description of research domain and analysis of overall satisfaction levels. Soc Sci Med 1988;27:637-644.

8. Sheftell FD, Tepper ST. New paradigms in the recognition and treatment of migraine. Headache 2002 (in press).

9. Lucas SL, Tepper SJ, Sheftell FD. Therapeutic gain and the triptans. In: Rapoport AM, Sheftell FD, (Eds). Seminars in Headache Management. Hamilton, Ontario. Decker Periodicals 1998;3:13-14.

10. US Physician Desk Reference. Sumatriptan, zolmitriptan, naratriptan, rizatriptan. 2000.

11. Sheftell FD, Fox AW, Weeks RE, Tepper SJ. Differentiating the efficacy of 5HT $1 \mathrm{~B} / 1 \mathrm{D}$ agonists. Headache 2001;41:257-263.

12. Goadsby P. A triptan too far? J Neurol Neurosurg Psychiat 1998; 64:143-147.

13. Sheftell FD, Fox AW. Acute migraine treatment: a clinician's view. Cephalalgia 2000;20(Suppl 2):14-24.

14. Cady RK, Sheftell F, Lipton RB, et al. Effect of early intervention with sumatriptan on migraine pain: retrospective analyses of data from three clinical trials. Clin Ther 2000;22:1035-1047.

15. Cady R, Lipton RB, Hall C, et al. Treatment of mild headache in disabled migraine sufferers: results of the Spectrum Study. Headache 2000;40:792-797.

16. Sheftell F, O'Quinn S, Watson C, Pait D, Winter P. Low migraine headache recurrence with naratriptan: clinical parameters related to recurrence. Headache 2000;40:103-110.

17. Tepper SJ, Donnan GA, Dowson AJ, et al. A long-term study to maximise migraine relief with zolmitriptan. Cur Med Res Opin 1999; 15:254-271.

18. Lipton RB, Stewart WF, Stone AM, et al. Stratified care vs step care strategies for migraine. The Disability in Strategies of Care (DISC) Study. JAMA2000,284:2599-2605. 
19. Primary Care Network. Patient-Centered Strategies for the Effective Management of Migraine. Springfield, MO; PCN Publishing. 2000.

20. Blau JN. Migraine. London, England. Chapman and Hall. 1987.

21. Sheftell FD, Weeks RE, Rapoport AM, et al. Subcutaneous sumatriptan in a clinical setting: the first 100 consecutive patients with acute migraine in a tertiary care center. Headache 1994; 34:67-72.

22. Graham JR. The headache patient and the doctor. In: Adler CS, Adler SM, Packard RC, (Eds). Psychiatric Aspects of Headache. Baltimore, MD: Williams and Wilkins;1987:34-55.

23. Edmeads J, Findlay H, Tugwell $\mathrm{P}$, et al. Impact of migraine and tension-type headache on life-style, consulting behavior, and medication use: a Canadian Population survey. Can J Neurol Sci 1993; 20:131-137.

24. Roter DL, Hall JA. Models of the doctor-patient relationship. In: Roter DL, Jall JA (Eds). Doctors Talking With Patients/Patients Talking With Doctors: Improving Communication in Medical Visits. Wesport, CT: Auburn House;1992:21-37.
25. Lipton RB, Stewart WF. Acute migraine therapy: do doctors understand what migraine patients want from therapy. Headache 1999;39 (Suppl 2):S20-S26.

26. Roter DL, Hall JA, Katz NR. Consequences of talk: the relationship of talk to patient outcomes. In: Roter DL, Jall JA(Eds). Doctors Talking With Patients/Patients Talking With Doctors: Improving Communication in Medical Visits. Wesport, CT: Auburn House; 1992:131-150.

27. Lipton RB, Goadsby PJ, Sawyer JPC, et al. Migraine: diagnosis and assessment of disability. Rev Contemp Pharmacother 2000;11:63-73.

28. Ware JE, Bjorner JB, Kosinski MA. Practical implications of item response theory and computerized adaptive testing, a brief summary of ongoing studies of widely used headache impact scales. Med Care 2000;38(suppl 2):11-73.

29. Headache Classification Committee of the International Headache Society. Classification and diagnostic criteria for headache disorders, cranial neuralgias and facial pain. Cephalalgia 1988;8(supp17):1-96. 